\title{
PAISAGENS DE AUSÊNCIA E DE VAZIO
}

Osvaldo FONTES FILHO ${ }^{1}$

- RESUMO: Este estudo procura evidenciar a natureza lacunar e intersticial da espacialidade própria à experiência sensível, segundo o último Merleau-Ponty, aquele da notas de trabalho de Le visible et l'invisible. Para tanto, são discutidos os momentos em que, no trato tanto com a perceptibilidade quanto com a intersubjetividade, Merleau-Ponty evoca a vida intencional a partir da analogia com a experiência estética em sua selvagem polissemia. O estudo especula que, apesar da evidência de que a plasticidade multimodal da arte moderna fornece renovado suporte para a interpretação da experiência sensorial, tarefa impossível para a racionalidade, a teoria do último Merleau-Ponty parece incapaz de propor uma noção consistente de negatividade.

- PALAVRAS-CHAVE: Merleau-Ponty, ausência, vazio, arte, intencionalidade, alteridade.

Sabe-se que para Merleau-Ponty o acontecimento da pintura moderna é emblemático de uma experiência encarnada. Quando, em razão da "deflagração do Ser", vacila o espaço trivialmente cúbico dos clássicos, "evidência do onde", a sensibilidade é convocada a se haver com uma iminência sempre diferida. Com isso, uma consciência do mundo necessariamente indireta, lateral, não-tética, é instada a se traduzir - na atitude estética - em trabalho sistemático de disjunção das formas. ${ }^{2}$ Rompido com os antigos im-

1 Professor Doutor do Departamento de Filosofia da Pontifícia Universidade Católica de São Paulo PUC-SP

2 Desengajado da figuração das coisas e da criação dos signos, o espaço pictórico moderno não é um continente pré-formado e indiferente a seu conteúdo. Se Henri Maldiney fala, a respeito, de um sensível ritmicamente apreendido é porque ruthmos distingue-se de skéma, como o continente vazio do cubo cênico dos Clássicos - onde formas espaço-temporais se manifestam em eterna evidência, atravessadas por um olhar analítico - distingue-se de um espaço que procede de seu conteúdo, ao sabor do que está em formação, fluido. "O ato de uma forma é aquele pelo qual uma forma se forma: ele é sua ontogênese" (Maldiney, 1973, p.157). Razão porque uma rítmica do aparecer é acolhida na superfície do quadro moderno - da "muralha de pintura", diria Balzac -, onde o olhar erra - diverge, divaga - ao sabor das vibrações das formas, cores e massas. O olhar é engendrado por essa errância mesma - "Logos das linhas, luzes, cores, relevos, massas" (Merleau-Ponty, 1964, p.71) -, segue as linhas de força de uma pluralidade atonal, isto é, desimpedida de uma gramática das formas. O ritmo latente e pregnante não se opõe ao espetáculo do caos: a ele se sobrepõe como seu reverso, como a invisível gênese ali das visíveis figuras, como forma em formação, Gestaltung. 
perativos da integra et bona forma, índice de presença peremptória, o artista moderno enfrenta o distante, o ausente. Descurado de uma profundidade mensurável, sua intencionalidade evolui no interior do que Merleau-Ponty chama a "voluminosidade", dimensão primeira onde as coisas se modelam na instabilidade, desimpedidas de suas circunscrições canônicas. Inquietar a canônica é aspirar à "espessura de um meio sem coisa", sorvedouro das oposições axiológicas do alto e do baixo, do dentro e do fora, da idéia e da matéria. ${ }^{3}$ Em suma, é devolver ao espaço seu assento carnal. Espaço que não é mais uma categoria ideal do entendimento, ele deverá voltar a ser o fundo despercebido de nossas experiências sensoriais. Mesmo se, para se fazer acessível como tal, tenha de desalojar hábitos perceptivos e cognitivos. Não afirma Merleau-Ponty (1964, p.35) que a pintura moderna "confunde todas as nossas categorias"? Talvez porque o moderno acredite apenas no que se desfaz e se refaz sob seus olhos. Seja como for, o espaço pictórico surge na dimensão de um encontro onde as instâncias objetivas sucumbem, onde o singular perde circunscrição, separa-se do aqui e do agora para vir compor com uma generalidade, com uma distância soberana.

L'oeil et l'esprit fala de atos de incisão, de fissuração, de abertura praticados no em si. Na pintura moderna, a linha é "certo vazio constituinte"

3 Na experiência da profundidade, paradigma ao qual o espaço em Merleau-Ponty é continuamente referido, o objeto visual dá-se à distância sem que se possa dizer que essa distância esteja claramente disposta a um sujeito que lhe faça a síntese. Na profundidade, o espaço dá-se à distância, como distância, isto é, retira-se e dissimula-se, sempre ao largo, iminência constantemente diferida. Desorientação que esclarece o regime originário do sentir. Enfim, se a profundidade distante é assim elevada à categoria de dimensionalidade fundamental, é de se imaginar que a pintura somente nela se implicará se for capaz de produzir uma voluminosidade "estranha" e "única", uma voluminosidade "mal qualificada", e que Merleau-Ponty concebia já na Phénoménologie de la perception segundo uma dialética da espessura e da profundidade: "é preciso redescobrir sob a profundidade como relação entre coisas ou mesmo entre planos, que é a profundidade objetivada, destacada da experiência e transformada em largura, uma profundidade primordial que dá seu sentido a esta e que é a espessura de um meio sem coisa. Quando nos deixamos ser no mundo sem assumilo ativamente, ou em doenças que favorecem essa atitude, os planos não mais se distinguem uns dos outros, as cores não mais se condensam em cores superficiais, elas difundem-se em torno dos objetos e tornam-se cores atmosféricas; o doente que escreve em uma folha de papel, por exemplo, deve atravessar com sua caneta certa espessura de branco antes de chegar ao papel. Essa voluminosidade varia com a cor considerada, e ela é como a expressão de sua essência qualitativa. Há portanto uma profundidade que ainda não tem lugar entre objetos, que, com mais forte razão, não avalia ainda a distância de um a outro, e que é a simples abertura da percepção para um fantasma de coisa mal qualificada" (Merleau-Ponty, 1945, p.307-8). As oposições axiológicas do alto e do baixo, do dentro e do fora, da idéia e da matéria cedem pois lugar a uma relação disjuntiva entre as formas que as demovem do anseio por consignar lugares. Esse esforço disjuntivo vem permear, a partir da experiência espontânea do visível, a arte moderna. Ainda: é de se perguntar se esse "fantasma de coisa mal qualificada", essa pura "voluminosidade", na mescla que propõe entre o volume construído e a opticalidade incircunscritível, não nos reconduziria às condições nas quais se dá a experiência estética da carne. É pela violência de uma incisão no que Merleau-Ponty chama "a carne das coisas" que a arte arranca a Natureza de sua retração. Permita-se, então, a hipótese: talvez Merleau-Ponty houvesse entrevisto a necessidade de liberar a arte de seu fundo humanista, feito do tráfico incessante do discurso; de fazê-la celebrar esse encontro com o Ser - nos entremeios da visão, no entrevisto dos diferentes aspectos, ativo e passivo - que, como ele diz comentando Klee, "torna impossível dizer que aqui acaba a natureza e começa o homem ou a expressão" (MerleauPonty, 1964, p.87). Pois é da intimidade dessa conjunção da natureza e do homem que parecem nascer, na inaparência do traço que vai às cegas, um mundo e suas paisagens lacunares. 
onde vibra a matéria. Através desse vazio, toda forma visível passa a carregar a elisão de uma figura ou de um sentido. Desimpedida dos contornos, na modulação que propõe das cores e das formas, a linha esboça uma fuga do sentido, como se, em seu caráter incoativo, o traço evidenciasse que doravante o sentido se constituirá sobre fundo de ausência, como obra da ausência. O vazio ou o "meio sem coisa" é o cenário preciso de um poder de formação, de modulação, de ressonâncias e de reverberações conquistadas a um espaço monolítico em sua positividade. Nesse sentido, o reinvestimento na materialidade/trama por parte do quadro moderno - cores, linhas, relevos, massas - visa esvaziar todo um repertório representativo-narrativo para fazer com que as formas suportem a carga de "configurações de ausência", ${ }^{4}$ lugares de expressão de uma ontogênese e de uma heterogênese.

Em face de tal engajamento, assegura Merleau-Ponty, a pintura moderna assume "significação metafísica"; as torções, reversões e transposições de sentido nela propostas, modos de compactuar com uma maneira ativa de ser, "fundam uma meditação filosófica". Mesmo porque, admite MerleauPonty (1964, p.63), um modo icônico qualquer pode valer como emblema de uma "mutação nas relações do homem com o Ser". Que estas a um dado momento tenham passado para o registro de um "vazio constituinte", há aí, como se verá, matéria para uma renovada explicação com a paisagem da experiência sensível.

Cumpre, de antemão, perguntar: como figurar uma elisão? Como presentificar uma ausência? Como fazer passar o Ser pelo elidido e pelo ausente, lugares de constituição de sua verticalidade e selvageria? Ser, aliás, que solicita da modernidade sua apresentação sem conceito. Uma dupla inscrição - da ausência do corpo visível e da presença dos seus paradoxais "movimentos sem deslocamento" - desloca por vezes a pintura moderna para o plano de imanência, convoca-a como forma auto-referida. É o que, ao comentar Klee, Merleau-Ponty assegura ser o que lhe fornece o caráter absoluto, como "princípio da gênese do visível". A arte celebra o devir sensível do autor e de suas épuras formais: duplo efeito da "concentração e vinda a si do visível". Razão porque, auto-figurativa, a pintura é dita "espetáculo de nada" (Merleau-Ponty,1964, p.75 e 69).

Espetáculo de nada ou espetáculo do nada? Como seria, afinal, uma "negação" significada por uma forma sensível? A questão tem razão de ser se for lembrado que Merleau-Ponty (1964a, p.270) fala de uma "não-presentabilidade originária" do invisível. Mas se esta não constitui uma negação

4 A expressão é empregada por José Gil (1996, passim) para significar o inconcluso irredutível das formas em suas transposições do espaço e do tempo. 
lógica ${ }^{5}$ como entender que de todo modo haja uma apresentação por negação dos modos de percepção do visível? Merleau-Ponty é a este respeito peremptório. Há como apresentar o visível "que está sempre 'mais longe'": ele deixa de ser inacessível se for concebido, não por aproximação, mas por "investimento lateral" (Merleau-Ponty, 1964a, p.270).

O corpo de percepção, "sensível exemplar", ajuda a compreender essa lateralidade. A transposição que ele propõe conduz à generalidade de horizonte por negação indireta deste ou daquele quale (desta ou daquela qualidade particular). Merleau-Ponty insiste na observação do processo pelo qual, a propósito da cor, uma singularidade sensível ganha sentido ao se transferir a uma generalidade. Para tanto, retém de Claudel que "certo azul do mar é tão azul que somente o sangue é mais vermelho" (Merleau-Ponty, 1964a, p.174). A metáfora consiste aqui em dizer o azul pelo vermelho. O azul e o vermelho são variantes na dimensão da cor. O azul é variante na dimensão do azul e compreende, por exemplo, aquele do mar, do céu, da liberdade, etc. $\mathrm{O}$ vermelho é variante na dimensão do vermelho que compreende, por exemplo, aquele do sangue, do fogo, da ira, etc. Mas esse azul e esse vermelho se cruzam em alguma inabitual equivalência que aponta para o fato de o azul do mar e o vermelho do sangue serem variantes de certa espessura viscosa, de uma profundidade surda, inquietante, quase obsedante: um e outro a faz ressoar à sua maneira. A frase de Claudel fissura assim a pontualidade do conteúdo sensível de uma e outra cor e sugere o parentesco originário que fornece "espessura" a esses conteúdos. A profundidade evocada é um eixo de possibilidades que o azul do mar cristaliza momentaneamente e que toca à distância o vermelho do sangue. A cor ver-

5 A recusa por parte de Merleau-Ponty de uma categorização lógica do invisível - a ausência não é "ausência objetiva [...] presença objetiva alhures, em um alhures em si" (Merleau-Ponty, 1964a, p.300) - entende articular seu estatuto ontológico como textura universal do sensível. O invisível não é um sentido positivo que finalizaria os jogos sintéticos da consciência perceptiva: dimensão de variação, ele confunde-se com suas próprias variantes, permanece nelas retido. O invisível não é senão o que articula cada momento perceptivo a todos os outros; ele explicita uma "negatividade natural, já aí desde sempre" (1964a, p.270), e que nunca se confunde com uma carência momentânea do sujeito. "É preciso compreender que é a visibilidade mesma que comporta uma nãovisibilidade"(1964a, p.300, grifo nosso). A carne não é fato nem qüididade, mas advento. Ela é o movimento de transposição próprio ao aparecer do mundo pelo qual cada atualidade é constituída em instância de devir, remetendo ao inatual a idéia de um real-em-si. O Ser bruto, autopossessão do mundo por si mesmo, advém ao se transpor ao invisível; ali, o estatuto do sentido não é outro senão o dessa negatividade natural que manifesta o sensível no movimento pelo qual ele se nega. Com o que falar de um mundo barroco, ser de promiscuidade, de polimorfismo, de incompossibilidade, não regido pelo universo domesticado de nossos pensamentos e finalidades, mas ordenado por um "princípio bárbaro" que, conquanto resista à fenomenologia, "não pode permanecer fora dela" (1960, p.225). Com isso, a fenomenologia encontra-se confrontada a uma "renovação do mundo que é também renovação do espírito, de redescoberta do espírito bruto não aprisionado por nenhuma das culturas, ao qual é pedido criar de novo a cultura" (1960, p.228). 
melha, emblemática de uma visibilidade simbolicamente saturada, emerge de uma "vermelhidão", configuração pré-individual do mundo donde a cor surge por individuações progressivas, conquanto não se estabilize em uma qüididade fechada em si. Enquadrado pelo olhar, o quale retoma sua existência atmosférica, pronuncia-se no horizonte de significâncias no qual inscreve seus valores diferenciais, concorrendo para a configuração temporal e espacial do mundo. Por um lado, é a visibilidade do mundo em sua generalidade que se pronuncia segundo a manifestação aparentemente episódica e pontual de uma qualidade sensível. Por outro lado, é a dimensão invisível dessa visibilidade esparsa que indicia a textura inerente à carne das coisas, sua possibilidade de agregar sentidos.

Nessa perspectiva, poder-se-ia falar do invisível como instância autêntica da negação: "potência" do visível, sua iminência. Correlativamente, evitar-se-á falar de uma positividade do visível como sublimação de negação: pregnância ou latência do invisível, o visível é continente de sua própria negação. De todo modo, a pontualidade do presente cede a uma virtualidade esparramada pela espessura do espaço e do tempo mais concreta que o medium indiferente do espaço e do tempo representados. O invisível é horizonte sobre o qual podem se destacar indefinidamente aparências e ilusões de aparências, formas e disjunções das formas. A atenção à labilidade irredutível do aparecer (do fenômeno) permite mesmo entender que a idéia que dele se pode ter é somente "uma espécie de precipitado ou de cristalização, embora sempre provisória, contingente e momentânea, de [sua] indefinida (ou in-finita) sutileza" (Richir,1987, p.85). Conseqüentemente, a experiência, instada a freqüentar esse meio naturalmente sutil do fenomênico, mais "velho" que as dualidades do fato e da essência, da pontualidade do atual e da extensão do potencial, opera possíveis que não se opõem obrigatoriamente à realidade do atual, mas que apontam para o alusivo de uma paisagem barroca do mundo sensível. ${ }^{6}$

6 Eis a estrutura merleau-pontyana do tempo, nos termos de Sérgio Cardoso (2000, p.356): "articulação e diferenciação latente do passado e do futuro no campo do presente, pois este guarda os traços de suas configurações passadas e evoca em si mesmo outras possíveis. Por isso não encontramos a temporalidade na sucessão (de diferentes momentos ou instantes) mas na simultaneidade desta presença espessa, movediça, permeada pelas marcas de um aquém e projetada para adiante pelos sinais do ausente inscritos nas suas dobras. Merleau-Ponty nos lembra, pois, ao se referir à espessura ou profundidade do presente, que ele não é 'um segmento de tempo de contornos definidos', uma duração determinada e contínua - como um indivíduo espaço-temporal -, mas um 'campo', aberto e 'poroso', indeciso e lacunar, em cujo inacabamento e indeterminação se encontra justamente sua abertura para o outro, para o ausente, ou ainda - para usar sua expressão mais cara - para o 'invisível', esta 'contrapartida secreta do visível... inscrita [permanentemente] nele, em filigrana'. Esta 'abertura' (inscrita no presente) é o elemento do tempo, pois é o motor da sua contínua diferenciação". 
As coisas espessam-se, ganham em generalidade, por negação de si próprias (como visíveis) na equivalência com as demais. Em vez de serem sínteses de uma mobilidade da nitidez, coexistem, escorregam umas nas outras, opõem obstáculo à sua inspeção, uma resistência que é precisamente sua realidade. Isto porque instanciam uma "existência atmosférica" na qual o corpo percepcionante está envolvido por todos os lados.

O filósofo merleau-pontyano, uma vez instruído pelo artista a considerar sua inevitável morada nessa generalidade, não pode mais assumir veleidades de puro espectador, o que lhe permitiria sobrevoar os dois lados de toda experiência e mensurar o trajeto da identidade à diferença, da presença à ausência. Resta-lhe a expectativa de mostrar por conceitos ou palavras, como o faz o artista com as formas, o que ocorre na indivisão das partes. E se é caso de falar aqui de um reposicionamento do filósofo - uma vez contra-efetuada a visão intelectual e evidenciado o intervalo interno da reflexão, seu "desfocado", sua incapacidade de coincidir consigo mesma -, ocorre considerar que "o único 'local' onde o negativo pode verdadeiramente existir é a dobra, a aplicação um ao outro do interior e do exterior, o ponto de virada" (Merleau-Ponty, 1964a, p.317). O que seria, afinal, a forma senão uma fertilidade inapreensível da dobra? O que seria o visível senão uma intensa e profusa topologia das dobras, uma trama generalizada na qual o interstício seria de algum modo portador da diferença, do sentido?

Não é, pois, casual que a ontologia de uma intencionalidade inscrita em um ser de indivisão, interessada em freqüentar os longínquos, venha justamente atravessar as paragens da dobra e, a partir dela, da virada e do verso, da transposição e da distância, da trama e da diferença; por fim, da modulação e da ressonância. O demonstrativo dessa travessia é uma vez mais a cor como quale visual, como textura, ou seja, como capacidade de "concreção de uma visibilidade universal, de um único Espaço que separa e reúne, que sustenta toda coesão" (Merleau-Ponty, 1964, p.85):

[... a virtude singular do visível que faz com que, mantido no término do olhar, ele seja, todavia, muito mais do que o correlato de minha visão, sendo ele que ma impõe como a seqüência de sua existência soberana [...] Este vermelho é o que é ligandose, do seu lugar, com outros vermelhos em volta dele, com os quais forma uma constelação, ou com outras cores que domina ou que o dominam, que atrai ou que o atraem, que afasta ou o afastam. Em suma, é uma espécie de nó na trama do simultâneo e do sucessivo [...] Certo vermelho também é um fóssil retirado do fundo de mundos imaginários. Se exibíssemos todas estas participações, perceberíamos que uma cor nua e, em geral, um visível, não é um pedaço de ser absolutamente duro, indivisível, oferecido inteiramente nu a uma visão que só poderia ser total ou nula, mas antes uma espécie de estreito entre horizontes exteriores e horizontes interiores sempre abertos, algo que vem tocar docemente, fazendo ressoar, à distância, diversas regiões do mundo colorido e visual, certa diferenciação, uma modulação efêmera desse 
mundo, sendo, portanto, menos a cor ou coisa do que diferença entre as coisas e as cores, cristalização momentânea do ser colorido ou da visibilidade. Entre as cores e os pretensos visíveis, encontra-se o tecido que os duplica, sustenta, alimenta, e que não é coisa mas possibilidade, latência e carne das coisas. (Merleau-Ponty, 1964a, p.174-5)

Em sua irredutível labilidade, em sua distorção originária, todo fenômeno está decalado em relação a si mesmo. Outro que o que parece ser, ele se deixa apreender em um "sistema diacrítico", em razão do "lago de nãoser" que contém e que implica sua abertura indefinida para outros fenômenos. Esse "não-ser qualificado" (Merleau-Ponty, 1964a, p.234), invisibilidade de toda presença, é o que faz a carapaça das aparências "soar oca": abrigo de todas as formas. Através desse hiato de ser, a aparência abre para a profundidade. Se ela não é mais quale projetável no plano da representação, se ela se mostra sempre situada à distância, é porque se fenomenaliza em uma aproximação que é afastamento, é porque advém do "fundo do invisível ainda que nele atolada", é porque há em sua carne uma distorção que faz de sua distância uma proximidade. ${ }^{7}$ Enfim, é próprio da aparência, uma estrutura de perversio que a faz gravitar entre o próximo e o longínquo, o fixo e o fugidio, e a se relançar sempre de sua própria ruína ou aporia. ${ }^{8}$ A aparência vincula-se ao tecido mundano em razão mesmo de seu não-fechamento, pelo fato mesmo de ela ser uma ruína oferecida ao fora, uma superfície em torcedura, em debate, conjunção de um dentro e de um fora que

7 Nesse sentido, procede a analogia da aparência com o efeito da muralha/trama de pintura: nesta, nos contam narrativas-chave como Le chef-d'oeuvre inconnu de Balzac, o espaço do diante (praesens), o plano do quadro, deixa-se modular por uma temporalidade da "eminência precipitada" (praesens), jogo irredutível do aparecimento-desaparecimento (cf. Didi-Huberman, 1985, p.59). O motivo tópico da trama é rico na história da pintura ao indiciar o jogo entre afastamento e aproximação, sôma e sema, local e global, detalhe e todo. É como tal que ele vem aqui caracterizar igualmente a intencionalidade.

8 Entenda-se aqui perversão da aparência no sentido do que posterga sua conclusão, do que impõe para sua fruição uma travessia (per) que incita obrigatoriamente tensão, retorno (versio), que se debate contra seu arremate (cf. Didi-Huberman, 1985, p.62-5). Explorar a analogia apresenta uma razão suplementar: sabe-se como a arte moderna rompe com a economia da superfície projetiva para fazer falar a espessura indutiva do suporte, ali onde os regimes de sentidos emergem do "folhado" da obra. No célebre "Dossier Ryman", Jean Clay podia então falar de um "triunfo [...] da espessura sobre o plano, da camada sobre a superfície", ou ainda, da "inter-relação das camadas e do trabalho de um sentido-acima-abaixo onde se desfaz a cena ilusionista, erodida por seu substrato textural e encontrando na ruína do efeito de real sua dimensão de inscrição simbólica [...]" (Clay, 1979, p.169). Um pensamento em obra excede necessariamente a ordem dos juízos determinantes ao se prestar ao jogo inesgotável das múltiplas "camadas" de sentido, aos movimentos de transdução criadores, em suas linhas de força, eixos de nervuras, campos de influências, redes de tensões. Inegavelmente, a trama pictórica - tessitura pensante na contraposição da inércia espacial da res extensa - é modelo tópico para a intencionalidade. 
nunca se recobrem com justeza. Há profundidade porque há distorção (deiscência) na aparência, porque um visível é "uma espécie de estreito entre horizontes exteriores e horizontes interiores sempre abertos" (MerleauPonty, 1964a, p.175). Há profundidade porque a aparência exige uma conversão do pleno em efeitos de pele: reticulado, interstício, passagem; exsudação, ressonância, modulação, diferenciação. Há profundidade porque o nó constitui a figura emblemática da aparência, figura tópica da tensão e da descontinuidade, da espessura e da invisibilidade, da travessia (per) que sempre garante um retorno (versio). Enfim, a perversão da carne é o registro veraz e voraz de toda experiência sensível.

O regime da carne permite constatar que, se o visível é "cristalização momentânea da visibilidade", ocorre de toda cristalização ser "ilusória sob qualquer aspecto". Isto porque "a visão é cristalização do impossível", pois "a pretensa positividade do mundo sensível [. ]. se verifica justamente como um inatingível" (Merleau-Ponty, 1964a, p.327 e 267-8). Está claro que a distorção da aparência representa uma impossibilidade de recobrimento absoluto do dentro pelo fora e do fora pelo dentro. Ora, parece então paradoxal o fato de Merleau-Ponty afirmar que essa distorção faz com que o mundo como tecido conjuntivo seja a aparência mesma que se manifesta, "coesão de si consigo", 'identidade em profundidade' (identidade dinâmica)" (Merleau-Ponty,1964a, p.262). Se ela promove o "advento do positivo", caso é que esse advento deve manter-se lacunar, inconcluso, instituição sempre ameaçada de destituição, não há mundo absolutamente positivo, mas quase-positivo ou ilusão-de-positivo.

Ora, em um primeiro momento, Merleau-Ponty reconhece um recobrimento impossível entre visível e invisível, silêncio e linguagem, vidente e visível, tocante e tangível, corpo e espírito, natureza e cultura. Contudo, em um segundo momento, a carne é tomada como o há único onde se arrematam as relações de reciprocidade entre aqueles termos (cf. Haar, 1999, p.256). "Meio formador do objeto e do sujeito", a carne parece carregar a deiscência como uma "prega" bem ordenada, um "sistema perfeitamente ligado", que "não é contingência, caos, mas textura que regressa a si e convém a si mesma" (Merleau-Ponty, 1964a, p.192-3), portanto perfeitamente harmonioso e transparente. Pergunte-se, então: um há carnal sem desmedida, sem reserva nem negatividade, não se estabeleceria sobre um esquecimento demasiado confortável do nada? Não-coincidência do corpo, ou melhor, "diferença dos idênticos" (Merleau-Ponty,1964a, p.316), o nada merleaupontyano seria - no dizer de Michel Haar - "uma figura plena e tranqüilizadora [...], a figura do nada mais benigna e a menos temível de toda a história da filosofia!" (Haar, 1999, p.34). 
Tal juízo apóia-se naqueles momentos em que o discurso de MerleauPonty assume a tematização de uma "sublimação da carne, que será espírito ou pensamento" (Merleau-Ponty, 1964a, p.191). Ciente de que o pensamento é indistintamente relação consigo, com o mundo e com outrem, Merleau-Ponty empenha-se em reportar essa concomitância à unidade do ver e do sentir. Ali, a economia do corpo esclarece uma centralização do que é espaço sem ter de reuni-lo a um pensamento do qual ver e sentir não seriam mais que modalidade.

Não propomos, aqui, qualquer gênese empirista do pensamento: perguntamonos, precisamente, qual é esta visão central que reúne as visões esparsas, este tato único que governa globalmente toda a visão táctil de meu corpo, este eu penso, que deve poder acompanhar todas as nossas experiências. Caminhamos em direção ao centro, procuramos compreender como há um centro, em que consiste a unidade, não dizemos que ele seja soma ou resultado e, se fazemos o pensamento aparecer sobre uma infra-estrutura de visão, é só em virtude desta evidência incontestada que é preciso ver ou sentir de alguma maneira para poder pensar, que todo pensamento que conhecemos advém de uma carne. (Merleau-Ponty, 1964a, p.191)

Essa carne, ao nomear uma dimensão ôntica única, é instada a circunscrever todas as dimensões, todas as maneiras de sentir. Totalização inesperada, diga-se. Além do que, um pensar apoiado nas estruturas da visão justifica-se plenamente em sua busca de um "centro", de uma "unidade" das visões esparsas. Afinal, pouco importa que a consciência intencional faça parte do campo da impercepção e, com isso, esteja "à mercê" de um invisível englobante. Como salienta José Gil (1996, p.42), "[Merleau-Ponty] parece contentar-se com definir a não-consciência do modo de apresentação do invisível de maneira puramente negativa, por referência à visão (consciente)". É porque o invisível manifesta-se ainda à consciência, entre os seus conteúdos perceptivos, que fica por se conceber modos outros de apreensão da ausência. De maneira que a carne merleau-pontyana, sempre descrita como maternal, "como quase doméstica", salienta Haar, não parece capaz, ao se sublimar, de reservar ao pensamento forças inquietantes, bem como a potência contraditória de abertura e de fechamento sobre si.

Seja como for, Merleau-Ponty aspira a "tomar ao pé da letra" o pensamento apoiado em estruturas de vazio e, com isso, "plantar este vazio no Ser visível, mostrar que ele é o seu avesso - em particular, o avesso da linguagem" (Merleau-Ponty, 1964a, p.289). "Tomar ao pé da letra" o modo de se produzir do pensamento não parece operação incompatível com a inspeção do avesso da linguagem onde, seguramente, o Ser tem a mostrar sua dinâmica diacrítica. Surpreende, porém, que o que se promete na sua literalidade, em contrapartida de toda uma "quinquilharia positivista", evoque proposições abertamente metafóricas tais como "o espírito brota na fissura do Ser". É co- 
nhecida a constância com que o último Merleau-Ponty - aquele das notas de trabalho de Le visible et l'invisible - se debate com a língua teórica nos momentos decisivos da argumentação. Talvez se pudesse falar aqui menos de um afastamento do estilo reflexivo (da adequação conceitual) que de uma disposição a pensar contemporaneamente à formação do objeto pensado. Nesse sentido, a nota de trabalho em questão parece ganhar clareza.

O nada merleau-pontyano é aquela zona de vazio e de invisibilidade na qual se insere toda manifestação visível. Ele não é negação frontal do ser pleno e maciço, negação a partir da qual estimar a adequação desta ou daquela aproximação conceitual. Na verdade, ele é condição de possibilidade do surgimento do Ser. É pois o intento de se ater a essa dimensão do nada, inscrita na junção dos entes, aberta para a metastabilidade do mundo, que explica a necessidade de renovar - até às fronteiras do conceitual e do metafísico - a expressão filosófica. Só se pode esperar que a "produção" de ser, encarregada de sentido, manifeste-se obliquamente, sem que tenha-se de falar de uma consciência "indireta", deixando transparecer, no reverso do ente, a zona invisível e a parte de vazio que lhe concedem fertilidade.

Uma vez que o nada está inscrito no coração do questionamento filosófico, promovendo-lhe seu élan, é dessa experiência ontológica do vazio, instalada nos lugares entrecruzados do mundo, que se espera depreender o advento do pensar como criação. Contudo, a indagação se impõe: seria essa experiência do vazio muito pouco selvagem? a carne, princípio bárbaro, seria "tenra demais"? - como estima Deleuze (1992, p.232).

Para começar a respondê-la, talvez fosse caso de considerar a operacionalidade que o vazio assume na linguagem plástica do modernismo. Neste, o que determina a fertilidade dessa ou daquela linguagem, conceito ou procedimento, é a sua capacidade de impedir o fechamento, a conclusão da totalidade. Afinal, pregnâncias são feitas de vazios, de brancos, de disjunções, de rupturas, de intervalos. Por isso mesmo José Gil afirma:

a relação vazio-forma faz doravante parte da linguagem do pintor: as variações nesta relação criarão outras linguagens, outros pintores no interior de um pintor, "heterônimos". O que permite passar de um heterônimo a outro, de um período a outro, não é a semelhança das formas, mas o que marca a diferença única e singular que atravessa a pintura de um autor, a sua maneira de produzir descontinuidades e intervalos: tal é o seu estilo, a diferença que sustenta o parentesco entre as formas visíveis. (Gil, 1996, p.166)

Gil fala ainda da substituição na arte moderna - sobretudo naquela conceitual - da evidência de sentido da figuração por um

vazio essencial, não só nesta evidência, mas no próprio ser da pintura, como se esta última doravante nunca mais pudesse bastar-se a si própria. A pintura moderna vai 
alimentar-se da tensão [...] entre completude e inacabamento, entre obra acabada e fragmento. Induzindo um movimento incessante de invenção de formas, o trabalho do vazio produz multiplicidades. É um vazio disseminado e ubíquo, que se encontra, por exemplo, na descontextualização, no exílio e na posição antifuncional do readymade [...]. Vazio inquieto que agita as formas e o olhar, que impede as aderências, que acelera as velocidades sempre em busca de um novo plano de expressão. (Gil, 1996, p.166) $)^{9}$

Esse "vazio disseminado e ubíquo", que explica "o movimento incessante de invenção de formas" na modernidade, prestar-se-ia ainda a emblematizar uma filosofia que persegue ao longo das múltiplas clivagens do Ser um sentido sem conceito dado a priori. Razão porque Merleau-Ponty evidencia seu registro em uma particular interioridade, diversa daquela do Ego constituinte: intentionaler Innerlichkeit, segundo a expressão tomada de Husserl. Intencionalidade que refere o lugar necessariamente não-simbólico, selvagem, da diferenciação entre as experiências; em outros termos, "nossa ausência na presença e nossa não-coincidência com os outros" (Merleau-Ponty, 1996, p.84). Assim, o mundo de que se tem experiência, "arquitetônica espaço-temporal", revela-se à semelhança da coisa heideggeriana: modulação no lugar de cruzamento de suas várias dimensões, constelação de sentidos, de atos e de visadas, enfim, o que se esgueira, o que se obtém por equívoco, o que se apresenta como excesso de si.

9 Sobre o particular regime do desenho como operação de estranhamento aos hábitos de apreensão intelectiva do olhar, é esclarecedora a análise de José Gil: "O olhar do desenhista não corre ao longo da linha contínua dos contornos objetivos, mas salta de um traço para uma sombra, deixa de ser táctil para se tornar óptico, desposa as descontinuidades lineares e as linhas de força, define espaços através de velocidades, etc. Este movimento que não se concebe fora de uma tipologia implica um olhar esburacante (ou 'penetrante'): porque é preciso desconstruir os espaços do objeto, é preciso analisá-los, é preciso decompô-los e neles produzir vazios [...] O vazio prepara o espaço para o exercício da imaginação. No seu tornar-se objeto, o desenhista tem portanto apenas que habita-lo do interior para nele criar um 'dentro' de onde resultarão todos os vazios visíveis. Depois do que, os seus planos, concavidades, superfícies se desarticularão: o vazio faz o seu trabalho a partir de dentro. Contém já em si uma pré-forma que dirige o movimento de desconstrução, uma 'forma do vazio' que desarticula e segundo a qual se desarticula o espaço. A atmosfera esboça essas pré-formas: por isso a atenção tensa do pintor visa apreender os movimentos atmosféricos a fim de neles recolher os intervalos do vazio [...] o vazio que dirige a desconstrução orienta já as formas por vir" (Gil, 1996, p.227-228). A descrição de Gil da desarticulação do objeto por parte do desenhista elucida a prerrogativa maior do que Merleau-Ponty chama o "pensamento mudo" do artista, qual seja, seu particular envolvimento, como corpo-de-visão, em uma operação desenfreada de avanço/recuo em relação a seu objeto; operação de construção de um objeto/corpo igualmente muito particular, "etéreo e infinitamente plástico", deslocado, torcido, desmembrado pelo movimento do desenho que "limita-se a retraçar-lhe a gênese, como se a recomposição ou a rearticulação dos espaços devessem necessariamente partir da sua origem" (1996, p.229). 
Nessa perspectiva, é possível conceber que pensamento e linguagem evoluem em um espaço de superposições, como "sistema de várias entradas" aberto para o recíproco ou para o interativo das ações transitivas, implicando em seu percurso um movimento que não é o de uma sucessão mas o de uma integração em profundidade dos vários planos - no "pulular de relações com duplo sentido", de incompatibilidades -, e, por fim, o de uma história que "gira em círculo ou marcha em ziguezague" (Merleau-Ponty, 1964a, p.125). Aliás, não é outro o modo de Merleau-Ponty definir o pensamento dialético:

é o que admite ações recíprocas ou interações - que admite, portanto, que a relação global entre um termo A e um termo B não pode exprimir-se numa única proposição, que recobre várias outras não sobreponíveis, mesmo opostas, definindo outros tantos pontos de vista logicamente incompossíveis e realmente mal reunidos, ainda mais: de que cada um destes conduz a seu oposto ou à sua própria inversão, chegando aí por seu próprio movimento [.]. é o que admite que cada termo só é ele mesmo voltando-se para o termo oposto, torna-se o que é pelo movimento, sendo a mesma coisa para cada um passar para o outro ou vir a ser si mesmo, sair de si ou entrar em si. O movimento centrífugo e o centrípeto são um único movimento porque cada termo é sua própria mediação, a exigência de um devir e até mesmo de uma autodestruição que produz o outro. (Merleau-Ponty, 1964a, p.123-4)

Se a filosofia entende afirmar-se como "exigência de um devir" que acompanha o movimento infindável de ir e vir entre o mesmo e o outro, então não será sem proveito nos reportarmos à questão da alteridade. Mesmo porque a experiência do outro, em vez de apontar para a exclusão mútua de consciências insulares, invoca uma vida generalizada, uma justaposição dos sentires no mundo, situação que traduz o sujeito de percepção na impossibilidade de se limitar à certeza íntima de suas percepções. Mesmo o ego reflexionante está de antemão condicionado pelo que Merleau-Ponty chama a "situação total", ou seja, o entrelaçamento entre as vidas, a confrontação entre os campos perceptivos, a mistura das durações. O mundo apresentado no caos do misto e na dinâmica das transferências entre ipseidades conduz para além das alternativas do objetivismo: a coisa visada "em minha cabeça", o outro "atrás de seu corpo"; o espírito como o que pensa, o mundo como o que é pensado. Na verdade, a experiência sensível como "não-saber" originário abre para o que não se é: excentricidade, capacidade de se ausentar de si. Ela desmonta assim a análise constituinte que, tratada do ponto de vista do fechamento do ego - todo objeto como unidade de sentido constituído no interior da psique -, desconsidera os sentidos vividos fora de si, no mundo.

Assumir a situação de retenção no tecido pré-analítico do Ser selvagem ou vertical - onde "passamos uns nos outros" (Merleau-Ponty, 1964a, 
p.257) -, impõe contornar conhecida tensão na operação reflexiva: interior ao ego haveria um ser cujo sentido é o de transcender esse ego. Essa tensão põe em jogo as duas dimensões constitutivas da metafísica: a exigência idealista, em virtude da qual o outro, como a coisa, deve aparecer como unidade de sentido; e a fidelidade à experiência que exige que o outro transgrida a esfera própria e faça surgir, nos limites do vivido, um suplemento de presença, incompatível com a inclusão de todo sentido nesse vivido.

Mas, pergunte-se, como é possível que se produza na interioridade um vazio capaz de abrigar uma outra consciência? Para a reflexão, bem o sabe Merleau-Ponty, não parece haver termo de compromisso entre a apresentação objetiva da ipseidade alheia e a sua condição de ipseidade. Assim que o outro é abordado a partir da oposição do alter e do ego, é sua transcendência que inevitavelmente se perde. Ora, a carne não é trânsito de intencionalidade a intencionalidade. A arte mostra que ela é, antes, modalidade rítmica da situação de "entrelaçamento do mundo com o espírito e do espírito com o mundo" (Merleau-Ponty, 1964a, p.72). Ocorre, porém, de a consciência constituinte não se reconhecer nessa situação. Na consideração de sua alteridade, por partir da solidão do ego, isto é, sob fundo de uma ausência do mundo, ela nunca se atém ao caráter eminentemente produtivo da tensão entre imanência e transcendência. Por um lado, a posição de outrem como outro-eu-mesmo não é de fato possível se é a consciência que a efetua: ter consciência de outrem seria constituí-lo como constituinte, e como constituinte em relação ao ato mesmo pelo qual é constituído. Por outro lado, a consciência não consegue descortinar a alteridade em si, o ser-o-outro-de-si-mesmo.

A percepção de outrem virá apenas daquelas particulares experiências onde, em razão de paradoxal permuta, o objeto intencional desengaja a intencionalidade. Somente uma percepção submetida à transcendência experimenta de fato a experiência do outro. Contra-efetuado por sua própria exteriorização, o corpo-de-carne que se preenche da espessura do mundo, que se abre para o que ele não é, supõe um retorno por parte do mundo que obscurece seu próprio corpo. Sem percebê-lo explicitamente, ele que está construído em torno dos arranjos internos do sensorium que o põem em condições de circunscrever os objetos do mundo, tem seu olhar sem cessar confrontado pela denegação dos sentidos desse mundo - toda forma corporal sempre supõe o "alhures" invisível de seu sentido. De modo que a experiência da visão jamais promove o desenrolar de um mundo objetivo diante de uma consciência ubiqüitária. Minha visão é aquela de um mundo que "me tampa a vista", cerca-me, excede-me; mundo não mais diante, mas em torno de mim. Esse envolvimento é, por princípio, irredutível a uma apreensão frontal. Embora eu esteja nele situado, não tem sentido a consignação precisa de um limite entre ele e mim, entre o que lhe pertenceria e o que eu 
possuiria como próprio. O próprio como circunscrição de um vivido, de um corpo sentido é desqualificado nesse fundo de indivisibilidade que é o mundo. ${ }^{10}$ A visão não se distingue do advento do visível, não se produz "em mim", mas alhures, junto à coisa. A exterioridade do mundo somente é acessível para uma experiência absolutamente fora de si mesma, ausente de si; que se confunde, enfim, com a espessura do mundo. Experiência de "visão total", como a chama Merleau-Ponty.

Uma vez mais, é possível surpreender essa visão total na experiência da percepção estética, ocasião de metamorfose do corpo na visibilidade que o envolve. Aí, o olhar obriga-se a abandonar a espacialidade por segregação do ponto de vista para ingressar na textura espacial maleável e indeterminada, em perpétua latência de determinação, das formas e das cores. Perceber esteticamente é tecer um plano do olhar que prolonga o plano espacial das formas. Nessa empresa, o olhar deixa de depender do corpo, deixa de se submeter a um ponto de vista. A respeito, esclarece José Gil:

o olhar deixa de estar fixado no corpo porque os próprios "lugares" do quadro se tornaram lugares de visão, o olhar é neles plenamente visão, já não vêm poisar neste ponto ou naquele, esse plano que une olhar e quadro mudou-se em corpo onde vidente e visto pertencem a uma única e múltipla visão. Já não há ponto de vista porque já não há corpo [...] Já não vejo o quadro, participo na "visão total" (Merleau-Ponty) que o corpo-plano oferece. Já não há ponto de vista, porque eu me torno cor, tornome forma e movimento das formas e das cores; não as vejo, mas é a própria visibilidade delas que sou. (Gil, 1996, p.305)

Radicalização da carne que carrega nos traços de uma dessubjetivação. O plano das formas e das cores potencializa a disposição natural que submete o corpo vidente e as coisas vistas à sua indefinição e espessura originárias. "Em vez de rivalizar com a espessura do mundo, a de meu corpo é, ao contrário, o único meio que possuo para chegar ao âmago das coisas, fazendo-me mundo e fazendo-as carne" (Merleau-Ponty, 1964a, p.178). Na instância da carne, eis a unidade originária do mesmo e do outro.

Tenra ou não, essa noção de carnalidade do mundo suscita ressalvas. Em seu regime, toda visão mostra-se variante de uma única Visão que somente garante sua unidade ao se diferenciar em visões distintas e insulares. Toda visão repousa sobre a espessura do Ser sensível, sobre um "cúmu-

10 De fato, "cabe-nos rejeitar os preconceitos seculares que colocam o corpo no mundo e o vidente no corpo ou, inversamente, o mundo e o corpo do vidente, como numa caixa [.]. Onde colocar no corpo o vidente, já que evidentemente no corpo há apenas 'trevas repletas de órgãos', isto é, ainda o visível? O mundo visto não está 'em' meu corpo e meu corpo não está 'no' mundo visível em última instância: carne aplicada à outra carne, o mundo não a envolve nem é por ela envolvido" (Merleau-Ponty 1964a, p.182). 
lo de subjetividade" que é também "cúmulo de materialidade" e, conseqüentemente, abertura em sua própria insularidade para os outros sentientes. A distância a outrem é "uma estranha proximidade" pois o sensível é, precisamente, "aquilo que sem se mexer do seu lugar pode assediar mais de um corpo" (Merleau-Ponty, 1960, p.23). O objeto cuja textura é interrogada pelo olhar não pertence a nenhum espaço de consciência: ele é matéria circulante entre os corpos de visão que, nessa circulação, deixam-se preencher pela carne universal do mundo. Uma "miraculosa multiplicação do sensível" esclareceria o que separa (ou une) as diferentes paisagens ao longo do tempo e do espaço, e o que faz de cada uma "um segmento da durável carne do mundo".

O visível que vemos, de que falamos é o mesmo de que falavam, que viam Platão e Aristóteles, o mesmo numericamente: por detrás de cada paisagem de minha vista, mesmo se não é o Himeto, o Ilissos ou os plátanos de Delfos, pois que é uma paisagem, não um grupo de sensações efêmeras, tampouco juízos, atos espirituais sem fogo nem lugar, mas um segmento da durável carne do mundo, estão escondidas as paisagens de todos os homens que existiram, de todos aqueles que existirão, de todos aqueles que teriam podido ou poderiam ser, indivisos entre eles e eu, como o objeto que detenho entre minha mão direita e minha mão esquerda. De Platão a nós, o homem grego desapareceu, um outro homem se fez, que coloca seu sabor próprio, seu próprio odor em tudo aquilo que empreende, mas quando ele lê Platão, quando segue no lá da Grécia antiga Platão e reencontra a nervura dos diálogos, então, no centro de si mesmo, e sincronicamente, algo se mexe e revive, algo que foi e é o pensamento de Platão. A Natureza e a Palavra, o visível e o escrito, de outro e do mesmo modo, recriam a cada instante uma simultaneidade universal. (Merleau-Ponty, 1996, p.374-5)

"O que foi e é" revive na unidade de um Si, em razão de sua participação na carne sem idade que o engloba! Como escapar da impressão que a paisagem presta-se aqui, uma vez mais, a um ponto de vista absoluto, sorvedouro das efemérides do vivido ${ }^{11}$

11 Uma outra paisagem, um outro olhar - que, aliás, não seria de todo hostil ao Merleau-Ponty de outros momentos - talvez possa falar a partir do ponto de vista do sentir: "Olho o campo aberto da paisagem. Aqui e ali, outros corpos idênticos ao meu surgem e, de súbito, a minha visão tolda-se, o fulgor das coisas embacia-se - não tanto na minha própria percepção dos objetos como no meu pensamento da paisagem. Obscurecimento sob o visível, encoberto nele, uma vez que nele nada mudou. Somente sei agora que nele alguma coisa me escapa, alguma coisa que eu não poderia ver. Tudo permaneceu semelhante, mas sinto que estes corpos agem como buracos negros cuja obscuridade, todavia, não é visível [...] Doravante, cada coisa é puxada na direção de pólos que se esgueiram à vista, entrando assim num espaço de possibilidades desconhecidas. Outros seres como eu vêem as mesmas coisas que eu e não sei o que eles vêem. A sombra projetada do corpo do outro se estende a tudo, criva a luz de incerteza e de dúvidas, carregando de desconhecido toda a evidência. O olhar do outro afeta o meu de um índice de cegueira. Mas a cegueira provoca a imaginação" (Gil, 1996, p.226). O espaço é aqui o da inscrição do desconhecido, espaço aonde a percepção vem buscar os alhures possíveis para passar do ponto de vista da visão, "situado no aqui objetivo do corpo próprio frente ao objeto percebido" (1996, p.227), para um ponto de vista situado no vago e indefinido, ou seja, no espaço estético ou da imaginação. 
A análise da experiência perceptiva mostrara a Merleau-Ponty que a individualidade da coisa sensível condiciona-se à participação na universalidade do mundo; a coisa percebida permanece pré-individual, sua singularidade é generalidade. $\mathrm{O}$ eu, do mesmo modo, situa-se aquém de sua oposição ao outro, confunde-se com uma generalidade que é "sincretismo", "transitivismo", "pré-egologia" (Merleau-Ponty, 1964a, p.274). Donde falar de um Ineinander, "tecido conjuntivo" que não é "nem objeto, nem sujeito", tampouco "alma do grupo"; que é, antes, "co-funcionamento" do eu e do outro, conjunção/disjunção, "superfície de separação entre mim e outro [...], lugar de nossa união, a única Erfüllung de sua vida e de minha vida" (Merleau-Ponty, 1964a, p.228, 268, 287). O discurso de Merleau-Ponty parece paradoxalmente interessado em localizar com precisão esse lugar intersticial. Mesmo porque

é em direção a essa superfície de separação e união que se dirigem os existenciais da minha história pessoal, ela é o lugar geométrico das projeções e introjeções, a charneira invisível sobre a qual a minha vida e a vida dos outros giram para balouçar de uma para outra, a membrura da intersubjetividade. (Merleau-Ponty, 1964a, p.287)

A relação com o outro acorre nesse ponto de contato que é também ponto de disjunção, nessa superfície de separação onde, ao se encontrarem, as individualidades são repelidas em direção à sua diferença - lugar onde se constituem a um tempo a diferença e a identidade das consciências e, conseqüentemente, a profundidade e a fenomenalidade do mundo. Razão porque Merleau-Ponty considera essa trama do Ineinander, do um-no-outro, como uma realidade última, irredutível. É somente por comodidade que ele fala de "consciências". Na verdade, não há consciências que resumiriam a profundidade do mundo à inconstância de um puro pensamento. "Não existe indivisível de pensamento, natureza simples [...] que ou é apreendida totalmente ou não o é, de uma forma total" (Merleau-Ponty, 1964a, p.327). Há, antes, dobra, charneira em torno da qual o mundo conquista sua unidade. Há "campos em intersecção, em um campo dos campos" (Merleau-Ponty, 1964a, p.281), de regime não causal, elemento no qual a unidade dos pólos carnais a um tempo se anuncia e se diferencia, anuncia-se ao se diferenciar.

Entende-se que esse co-funcionamento dos incompossíveis constitua a "plasticidade" por assim dizer do mundo enquanto continente dos esforços conjuntos de junção e disjunção. Contudo, ocorre que o apelo a uma "visibilidade anônima" - que habitaria simultaneamente o eu/presença e o outro/ausência, o pleno e o vazio - força a trabalhar com a idéia de uma "visão em geral", em virtude mesmo da propriedade primeira da carne, qual seja, a de ser indivíduo, sendo igualmente dimensão e universal (cf. MerleauPonty, 1964a, p.187-8). Ora, Merleau-Ponty é levado mesmo a considerar um 
"Sentiente em geral" passível de abrigar essa universalidade. ${ }^{12} \mathrm{O}$ que não lhe poupa de severas censuras. Assim, Michel Haar:

Se a carne vê, "pensa" - assim como o corpo "pensa", isto é, realiza sínteses significantes, como por exemplo compreender formas, excluir ou incluir, orientar-se espontaneamente segundo o alto e o baixo, a frente e o fundo, etc. - , onde terminaria a carne pois que ela é universal? Ela incluiria a matéria ou terminaria no vivente? A noção de um "Sentiente em geral" reconduziria, se seguíssemos suas últimas conseqüências, a um pitagorismo romântico, descabelado. (Haar, 1999, p.19)

E, na seqüência, ao comentar a impropriedade da idéia de "corpo único", Haar afirma:

A dificuldade principal está no fato de que essa posição do Ser como dimensão de todas as dimensões, que encerra "a expressão de todo ser possível", engloba dimensões tão diferentes quanto a vida orgânica, a percepção, o pensamento e a linguagem! Como admitir que seja o Ser, isto é, a carne, que pensa e não nós! (Haar, 1999, p.22)

Ressalvas à parte, retornemos à ubiqüidade da experiência perceptiva do outro. Ali, o olhar erra entre os elementos da aparência de um volume que permanece ocluso. Visada em seu corpo exterior, posta diante de nós, da interioridade de outrem temos de nos contentar com índices, signos de uma presença de fato longínqua, vivida em defasagem da nossa. Dela não se obtém mais que certa forma de ausência. E, no entanto, é a essa ausência que nos reportamos. Onde situar esse nada, esse distante que há "dentro"? Somente um cartesiano teria resposta peremptória para a questão: o objeto está na extensão, ao passo que o conteúdo vivido encontra-se fora dela, "dentro", na psique (cf. Gil, 1996, p.169). Ora, de certo modo o invólucro contém um vazio, mas um vazio particular posto que é mais que ausência de matéria: é vida vivida "alhures", em simultaneidade com esta minha, em hiato com ela. Uma vez que é aí que o outro se abriga, é daí que me fala.

O vivido de outrem sempre escapa a meu olhar, é escolho no preenchimento de minha intencionalidade. Em compensação, a não-presença que ir-

12 Lê-se: "Cada visão monocular, cada palpação de uma única mão, embora tenha seu visível e seu tangível, está ligada à outra visão, à outra palpação, de modo a realizar com elas a experiência de um único corpo diante de um único mundo, graças a uma possibilidade de reversão, de reconversão de sua linguagem na delas, possibilidade de reportar e de revirar segundo a qual o pequeno mundo privado de cada um não se justapõe àquele de todos os outros mas é por ele envolvido, colhido dele, constituindo, todos juntos, um Sentiente em geral, diante de um Sensível em geral" (Merleau-Ponty, 1964a, p.186). 
radia em todas as formas de seu corpo é o que garante a relação polissêmica com ele. O outro é irredutível a um corpo-de-carne fechado sobre si. Cristalização momentânea de um viver, encarnação de uma vida, todos os seus movimentos, em seus intervalos, modulações, mudanças de orientação, são diferenciações de uma mesma dimensão, momentos de uma única abertura para o mundo, referidos em sua própria singularidade a outros gestos possíveis. Esses gestos, não situáveis sobre o plano objetivo, submetidos pois à alternativa do movimento e do repouso, não se sucedem de maneira descontínua mas deslizam uns nos outros: dão testemunho da unidade de uma potência, de um "eu posso" cuja capacidade não tem medida objetiva. Não há localização fixa de um outrem; observado em seu movimento, o que de fato se vê é a dinâmica difusa de um desdobramento de mundo. Não há, por um lado, um corpo objetivo e, por outro, movimentos que o animam. Há, ao contrário, um único visível que, em todos os pontos de si mesmo, dá-se como diferenciação de certo modo de abertura para o mundo.

Mas, afinal, onde estaria o outro nesse corpo que vejo? Merleau-Ponty recorre aqui, uma vez mais, à analogia com a obra de arte:

Ele é (como o sentido da frase) imanente ao corpo (não se pode destacá-lo para pô-lo à parte) e, contudo, é mais do que a soma dos signos ou significações por ela veiculados. É aquilo de que as significações são sempre imagens parciais e não exaustivas, - e que contudo atesta estar presente por inteiro em cada uma delas. Encarnação inacabada sempre em curso - Para além do corpo objetivo como o sentido do quadro está para além da tela. (Merleau-Ponty, 1964a, p.263)

O fenômeno do outro caracteriza-se por sua estrutura diacrítica: assim como a realidade do significante procede das oposições e dos parentescos de que participa, a realidade do corpo de outrem nasce da incessante diferenciação de seus comportamentos. Mais que a soma de seus signos visíveis, o outro é encarnação de sentidos que, ao mesmo tempo, retém um inexprimido irredutível. À semelhança da palavra, é "massa trabalhada do interior por uma espécie de ebulição"13 que a abre para os jogos intermináveis de investimento no Ser. Assim, embora cada gesto forneça do outro somente uma "imagem parcial e não exaustiva", ele atesta-se "por inteiro em cada uma delas", subsiste tão somente como suas diferenças, isto é, segundo as configurações (comportamentos) nas quais advém. Assim como a frase, o sentido do outro preserva sua riqueza porque permanece retido nos signos que o dão a entender. O outro está entre seus gestos visíveis, em sua juntura, imerso em um corpo vivo, investido pelos comportamentos que ele

13 A expressão aparece em manuscrito inédito, mas ressurge quase idêntica em Le visible et l'invisible (1992, p.193) para designar a noção de "carne". 
próprio investe. Por isso é possível falar a respeito do outrem como de uma iminência sempre diferida: à semelhança da coisa percebida, outrem permanece longínquo, sua presença é, por assim dizer, "atmosférica". "Como o corpo próprio, é preciso dizer de outrem que ele não está alhures, mas não se pode dizer que ele esteja aqui ou agora no sentido dos objetos" (MerleauPonty, 1964a, p.272). ${ }^{14}$ O sensível nunca se apresenta sob a forma de um indivíduo acabado, pacificado em seu espraiamento partes extra partes; assenta-se, antes, em "falsa base", ao lado do ponto onde é procurado, irradiando a outros pontos. Analogamente, o outro não se manifesta como consciência, princípio de síntese, sensível insecável, mas como eixo de coesão em torno do qual se constitui o mundo como sua complementaridade. Um mundo jamais se manifesta na plena exterioridade, mas a aparição do outro corresponde a um acréscimo de sua "massa interiormente trabalhada" por força da alusão de cada sensível a todo outro. Na verdade, a filosofia da carne situa o mundo tanto aquém da interioridade quanto além da exterioridade. Ela o pensa como concreção de um Si universal que, em virtude dessa universalidade, apresenta-se inclinado a se pluralizar.

Assim, outrem se assemelha à obra de arte como modo de articulação do mundo por recortes em sua espessura. De fato, ele é como um sentido encarnado cujas manifestações são signos indefinidamente fluidos, errantes. Esse sentido assemelha-se ao de um quadro por seu caráter kantianamente "estético", isto é, como um sentido sem conceito dado a priori - conceito que reificaria o outro, ou o projetaria sobre o plano do Mesmo. Esse sentido se faz na temporalização originariamente intersubjetiva da implicação das lacunas do outro nas minhas, no interior de um Ser-de-múltiplas-entradas. De fato, há algo da vida de outrem que sempre me escapará, assim como é através de outrem que chego a compreender que há algo de minha própria vida que sempre me escapará. Donde a imbricação intersubjetiva não ser intersecção entre duas positividades, mas "junção à distância" (Merleau-Ponty, 1964a, p.287), modo de se encontrar em algum lugar, no "alhures".

Falava-se acima de uma "superfície de separação entre mim e outro", superfície que é também de junção, em torno da qual giram os existenciais para se entrecruzarem e se entretecerem uns aos outros na "membrura da intersubjetividade". Se Merleau-Ponty escreve que ela é "lugar geométrico das projeções e introjeções", a expressão trai tão somente o caráter provisó-

14 Na gestão que o outro impõe de uma iminência sempre diferida, ele acompanha o que em pintura constitui a contestação da linha prosaica, conformadora dos limites: "nem o contorno da maçã, nem o limite do campo ou do prado estão aqui ou ali, mas sempre para cá ou para lá do ponto a partir do qual se olha, sempre entre ou atrás daquilo que se fixa, indicados, implicados, e mesmo muito imperiosamente exigidos pelas coisas, mas em si mesmos não são coisas" (Merleau-Ponty, 1964, p.73). 
rio das notas de trabalho de Le visible et l'invisible. Na verdade, o esforço aqui é antes o de garantir para a Weltlichkeit dos espíritos (em curso de encarnação inacabada) outra espacialidade que não a da extensão positiva. Esta, de fato, não dá conta dos entrecruzamentos múltiplos e selvagens onde se ancoram os existenciais, verdadeiras constelações invisíveis que disseminam os sentidos.

A questão do outro insinua a complexidade de um pensamento dos sentidos como existenciais encarnados, pensamento que, aliás, oferece uma perspectiva renovada do inteligível para além do "universo das significações" ou das "coisas ditas". Ela permite, ainda, apreender toda a dimensão de não-presença, de ausência da vida de outrem na minha, e a maneira pela qual essa ausência se distribui em lacunas, em buracos de ausência na presença que dão ao sentido os horizontes fenomenológicos de sua profundidade. Leia-se, a propósito, a seguinte nota de trabalho:

Fala-se sempre do problema do "outro", de "intersubjetividade", etc... Na realidade, o que se deve compreender é, além das "pessoas", os existenciais segundo os quais nós as compreendemos e que são o sentido sedimentado de todas as nossas experiências voluntárias e involuntárias. Este inconsciente a ser procurado, não no fundo de nós mesmos, atrás das costas de nossa "consciência", mas diante de nós como articulações de nosso campo. É "inconsciente" porquanto não é objeto, sendo aquilo por que os objetos são possíveis, é a constelação onde se lê nosso futuro Está entre eles como o intervalo das árvores entre as árvores, ou como seu nível comum. É a Urgemeinschaftung de nossa vida intencional, o Ineinander dos outros em nós e de nós neles.

São esses existenciais que constituem o sentido (substituível) daquilo que dizemos e ouvimos. São eles a armadura deste "mundo invisível" que, com a fala, começa a impregnar todas as coisas que vemos, - como o "outro" espaço nos esquizofrênicos toma posse do espaço sensorial e visível - Não que, por sua vez, ele o venha a ser: nunca há no visível senão ruínas do espírito, o mundo sempre se assemelhará ao Fórum, pelo menos aos olhos do filósofo, que não mora nele inteiramente. (Merleau-Ponty, 1964a, p.233-4)

O trecho é seminal para o entendimento da questão da alteridade, mas, por investi-la a partir de figuras - revelando a necessidade de inaugurar uma tópica -, exige uma leitura mais cuidadosa. O que se tentará a seguir, em guisa de conclusão.

Merleau-Ponty fala nesta nota da Urgemeinschaftung da vida intencional, a formação de sua comunidade originária, o quiasma dos outros em nós e de nós neles. É paisagem de invisibilidade, que a nota caracteriza como um campo de ruínas do espírito. Quanto aos existenciais, "são o sentido sedimentado de todas as nossas experiências voluntárias e involuntárias". Histórica, a facticidade verifica-se comunitária, pois que é o depósito sedi- 
mentado aonde o sentido da experiência humana vem, por assim dizer, se inscrever (cf. Richir, 1992, p.10). Por sua constituição sedimentária, a estrutura existencial cliva-se em multiplicidades de possíveis existenciais, cujos sentidos são constelação de sedimentos que estruturam a priori a experiência do mundo. Essa constelação é articulação de campo, no interior da qual ganham sentido pro-jetos, isto é, onde "se pode ler nosso futuro". Se essa leitura se faz por intervalos, por nivelamentos, ela confirma um vivido aberto para seus outros, e um inconsciente sem conteúdo positivo, simples sedimentações plurais, indefinidamente múltiplas, de sentidos. Feito por assim dizer de vazios, "ele é como o intervalo das árvores entre as árvores", produz a profundidade (o espaçamento/a espacialização) da experiência, sua paisagem. É nos vazios das articulações ou das constelações invisíveis de adesão ao Ser que se aloja o sentido substituível do que se diz e se entende. Assim, a palavra não é a disposição temporal de significações já feitas. Ela constitui a maneira comunitária (o "nível comum") pela qual cada palavra ou pensamento aciona a viscosidade dos sentidos por entre as estruturas existenciais e invisíveis de sentidos já sedimentados.

Cumpriria falar aqui de uma descrição renovada de toda a paisagem interhumana, nos termos da articulação dos existenciais entre os atos e visadas e não por detrás deles. Mesmo porque, arremata Merleau-Ponty (1964a, p.269), “a Weltlichkeit dos espíritos é assegurada pelas raízes que estes lançam, não certamente no espaço cartesiano, mas no mundo estético".

FONTES FILHO, Oswaldo. Landscapes of absence and emptiness. Trans/Form/Ação, (São Paulo), v.31(1), 2008, p.105-126.

- ABSTRACT: This paper attempts to display the lacunar and interstitial spatiality of the sensible experience in Merleau-Ponty's later working notes to The visible and the invisible. For that purpose, it discusses some Merleau-Ponty's statements about perceptibility and intersubjectivity where is evoked the intentional life through an analogy to esthetical experience and its savage polissemy. Furthermore, this paper speculates that, although the evidence that the multimodal plasticity revelead by modern art provides renewed support for interpretating sensory experiences - impossible task for rationality -, late Merleau-Ponty's theory seems unable to propose a consistent notion of negativity.

- KEYWORDS: Merleau-Ponty, absence, emptiness, art, intentionality, alterity.

\section{Referências bibliográficas}

BARBARAS, R. De l'être du phénomène. Sur l'ontologie de Merleau-Ponty. Grenoble: Jérôme Millon, 1991, p.376. 
CARDOSO, S. O olhar viajante (do etnólogo). In: Adauto Novaes et al., O Olhar. São Paulo: Companhia das Letras, 2000, p.347-60.

CLAY, J. La peinture en charpie. Macula (Dossier Ryman). 5/6. 1979, p.167-86.

DELEUZE, G. O que é a filosofia? Rio de Janeiro: Editora 34, 1992, p.191.

DIDI-HUBERMAN, G. La peinture incarnée. Paris: Minuit, 1985, p.167.

GIL, J. A imagem-nua e as pequenas percepções. Estética e Metafenomenologia. Lisboa: Relógio D’Água Editores, 1996, p.330.

HAAR, M. La philosophie française entre phénoménologie et métaphysique. Paris: PUF, 1999, p.142.

MALDINEY, H. Regard Parole Espace. Lausanne: Editions L'Age d'Homme, 1973, p.172.

MERLEAU-PONTY, M. Signes. Paris: Gallimard, 1960, p.430.

Phénoménologie de la perception. Paris: Gallimard, 1945, p.531.

. Le visible et l'invisible. Paris: Gallimard, 1964, p.360.

Notes des cours 1959-1961. Paris: Gallimard, 1996, p.402.

L'oeil et l'esprit. Paris: Gallimard,1964, p.92.

RICHIR, M. Communauté, société et histoire chez le dernier Merleau-Ponty. In: Merleau-Ponty. Phénoménologie et expériences. Grenoble: Jérôme Millon, 1992. p.7-26.

Essences et "intuitions " des Essences chez le dernier Merleau-Ponty. In: M. RICHIR. Phénomènes, Temps et Etres. Ontologie et Phénoménologie. Grenoble: Jérôme Millon, 1987, p.65-103. 